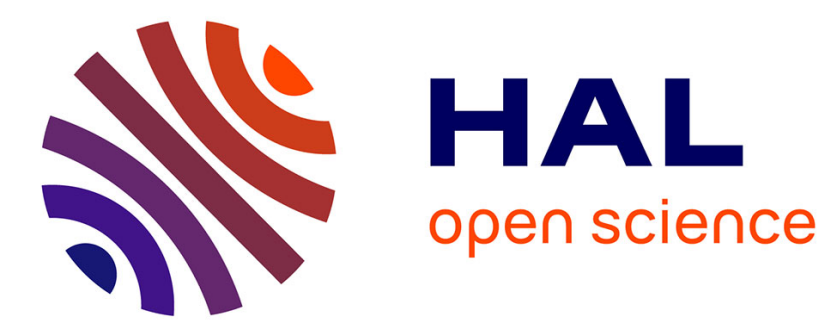

\title{
Numerical Modelling of an Innovative Microwave Assisted Freezing Process
}

Mathieu Sadot, Sébastien Curet, Olivier Rouaud, Alain Le-Bail, Michel Havet

\section{To cite this version:}

Mathieu Sadot, Sébastien Curet, Olivier Rouaud, Alain Le-Bail, Michel Havet. Numerical Modelling of an Innovative Microwave Assisted Freezing Process. International Journal of Refrigeration, 2017, 80, pp.66 - 76. 10.1016/j.ijrefrig.2017.04.017 . hal-01902412

\section{HAL Id: hal-01902412 \\ https://hal.science/hal-01902412}

Submitted on 23 Oct 2018

HAL is a multi-disciplinary open access archive for the deposit and dissemination of scientific research documents, whether they are published or not. The documents may come from teaching and research institutions in France or abroad, or from public or private research centers.
L'archive ouverte pluridisciplinaire HAL, est destinée au dépôt et à la diffusion de documents scientifiques de niveau recherche, publiés ou non, émanant des établissements d'enseignement et de recherche français ou étrangers, des laboratoires publics ou privés. 


\title{
Numerical Modelling of an Innovative Microwave Assisted Freezing Process
}

\author{
Mathieu SADOT ${ }^{1}$, Sébastien CURET ${ }^{1}$, Olivier ROUAUD ${ }^{1}$, Alain LE BAIL ${ }^{1}$, Michel \\ HAVET $^{1^{*}}$
}

${ }^{1}$ ONIRIS, Université de Nantes, GEPEA, CNRS,

Rue de la Géraudière - CS 82225 - 44322 NANTES CEDEX 3

*(corresponding author: michel.havet@oniris-nantes.fr)

\section{Highlights}

- An innovative pulsed microwave assisted freezing process was modelled

- Phase change was modelled using enthalpy formulation including ice crystal growth

- Thermophysical and dielectric properties were linked to the ice fraction

- Influence of microwave pulses on temperature oscillation amplitude was highlighted

- Freezing front location and reflection influence hot-spot displacement

\begin{abstract}
This study aimed to model an innovative process of pulsed microwave assisted freezing (MAF), which was expected to improve frozen product quality. The phase change model was based on spherical ice crystal growth and an original enthalpy formulation. The objective was to understand better the thermal interactions between microwaves and a product being frozen in a TE10 waveguide in which nitrogen gas and microwaves reach the product on the top surface. The $2 \mathrm{D}$ model was validated against the literature data and used to perform numerical simulations. The freezing front location and the reflection at air-product interfaces have a large impact on microwave behaviour in the product, especially on hot-spot displacement. As in some experimental works, temperature oscillations were observed. It is shown that their amplitude is related to the pulse duration. These results will help in designing experimental procedures to study the interest of using low energy pulsed microwaves during freezing.
\end{abstract}

\section{Keywords:}

Freezing; Pulsed Microwaves; Modelling; Crystallisation; Ice Fraction

\section{Introduction}

Freezing is widely used in the food industry; it preserves organoleptic (texture, taste, appearance) and nutritive (vitamins, minerals) product quality while reducing chemical reaction rates (Lim et al., 2004) and controlling microbial activity (Bremer and Ridley, 2004) due to the low storage temperature. Freezing is usually considered achieved when a given food reaches the temperature of $-18^{\circ} \mathrm{C}\left(0^{\circ} \mathrm{F}\right)$ or lower, in order to turn most of its liquid water into ice (International Institute of Refrigeration, 1986). However, only partial crystallisation of water is obtained at $-18^{\circ} \mathrm{C}$, which can result in quality changes, ice recrystallisation or further chemical reactions caused by increasing solute concentration in unfrozen matrices or by changing reaction conditions such as $\mathrm{pH}$ or ionic strength (Lim et al., 2004). The quantity of ice formation depends not only on temperature but also on the product composition, e.g. for 
meat at $-20^{\circ} \mathrm{C}, 89 \%$ of water is frozen and complete crystallisation is achieved at $-65^{\circ} \mathrm{C}$ whereas for carrots at $-20^{\circ} \mathrm{C}$, only $54 \%$ of water is frozen (Wang and Weller, 2012).

The quality of a frozen product is linked to the size of ice crystals. Freeze damage is usually lower for smaller crystals (Delgado and Sun, 2001). In fact, large ice crystals damage cell membranes due to water expansion during the phase change (Kalichevsky et al., 1995; Pham, 2006). This volume increase exerts a larger pressure and mechanical damage on cell membranes, which can crack and cause loss of mass during thawing (Bevilacqua et al., 1979; Delgado and Sun, 2001). Another explanation for larger drip loss due to bigger ice crystals is the smaller specific surface area, which decreases the water reabsorption during thawing (Bevilacqua et al., 1979).

It is known that faster freezing enhances frozen food quality while forming smaller ice crystals (Devine et al., 1996) but fast freezing processes (e.g. cryogenics) are energydemanding (Chourot et al., 2003; Dempsey and Bansal, 2012). It is therefore a challenge to reduce process costs without increasing ice crystal size or to reduce ice crystal size without dramatically increasing costs. Some new freezing processes are being developed to control ice nucleation with the help of ultrasound, a magnetic field, AC or DC electric fields, mechanical agitation, or a pressure shift (Dalvi-isfahan et al., 2017; Le Bail et al., 2002; Woo and Mujumdar, 2010; Xanthakis et al., 2014).

Some experimental studies have shown that it is possible to obtain smaller ice crystals by using electromagnetic wave assisted freezing: Hanyu et al. (1992) reported better ultrastructural preservation and smaller ice crystals in squid retina frozen by contact on copper at $83 \mathrm{~K}$ with microwave assistance at $2.45 \mathrm{GHz}$. Jackson et al. (1997) obtained less ice and more glass in an aqueous ethylene glycol solution frozen by quenching in liquid nitrogen with microwave assistance at $2.45 \mathrm{GHz}$. Anese et al. (2012) froze pork meat with pulsed radio frequency assisted nitrogen spray freezing and obtained smaller ice crystals and better colour preservation. More recently, Xanthakis et al. (2014) detected smaller ice crystals and a decrease in the degree of supercooling for pulsed microwave $(2.45 \mathrm{GHz})$ assisted freezing with a heat exchanger at $-30^{\circ} \mathrm{C}$. In this last study, temperature oscillations due to microwave pulses were observed.

These innovative freezing strategies are expected to produce high quality frozen foods with less energy consumption due to the fact that ice crystallisation is influenced by an external cause (electromagnetic disturbance, ultrasound, etc.); the freezing process could thus be carried out in less intensive conditions (lower air velocity, higher ambient air temperature). Consequently, it would be economically interesting compared to cryogenic freezing (Mallett, 
1993). Nevertheless, the optimisation of these new processes requires that all the phenomena responsible for improving ice nucleation are well understood.

In our work, the alternative electric field induced by microwaves involves water molecule rotations because of the alignment of their electric dipole with the electric field $(2450 \mathrm{MHz})$. On one hand, these rotations interfere with the H-bond network between water molecules, which could be a crystalline structure precursor. This is one hypothesis to explain the inhibition of ice formation (Hanyu et al., 1992). On the other hand, it generates heating by water molecule deformation and friction (Akkari, 2007; Curet, 2008) and the energy dissipated by microwaves induces a partial melting of ice crystals. This may favour ice crystal dislocation and, in turn, a higher number of ice crystals. The small temperature rise induced by microwave pulses is followed by a rapid temperature decrease. Xanthakis et al. (2014) proposed that the partial melting due to these temperature oscillations could induce a secondary nucleation. As part of the European project FREEZEWAVE (FP7-ERA-Net SUSFOOD), the purpose of this study is to obtain a better understanding of the interactions during MAF.

MAF is a complex process because the heat generated by microwaves is linked to the amount of free water in the fresh product. In fact, the local electric field strength and dielectric loss factor, responsible for the heat generated by microwaves, are directly linked to the liquid water content (Tang, 2005). The dielectric loss factor, like the dielectric constant, decreases when frozen water increases because ice has a lower loss factor than liquid water (Basak, 2003). The dielectric properties of products that have a high water content, such as food products, decrease during freezing (Nelson and Datta, 2001). Below the initial freezing temperature, the temperature drop involves a decrease in the heat generated by microwaves. Furthermore, the spatial distribution of the electric field is not homogeneous within the product, oscillating between nodes, where the electric field is weak, and antinodes, where the electric field is strong. These places are linked to the dielectric constant of products, which evolves with the frozen water content. Within homogeneous materials with a large thickness compared to the microwave penetration depth, the electric field is exponentially attenuated as a function of depth (Lambert's law) (Liu et al., 2005). If the thickness of the product is of the same magnitude as the penetration depth in the material, resonance occurs (Curet et al., 2009) because of internal reflections. When an electromagnetic wave is propagating successively through a totally or partially transparent environment with different dielectric properties, a reflection occurs at the interfaces (Dibben, 2001). Even if a part of the microwaves passes through an interface, this can be considered a "partial shortcut" and some power is reflected resulting in a standing wave. In the freezing process, dielectric properties decrease locally 
with time (freezing of water). Therefore, electromagnetic waves should penetrate deeper in the product and thus the electric field attenuation should be smaller. This could induce resonance in the product during freezing.

Even if temperature can be locally measured by optical fibres it is very difficult to perform experiments to quantify the spatial and temporal evolution of thermal and electromagnetic variables (temperature, electric field strength) and their effects, such as resonance or the development of hot spots. As simulation appears a promising alternative, an original numerical model of MAF was developed. To our knowledge, the current study is the first to provide a deep analysis of these complex mechanisms.

\section{Model development}

\subsection{Configuration}

In the literature, MAF experiments have been carried out to analyse the effect of the electromagnetic field on food and animal tissue quality (Anese et al., 2012; Hanyu et al., 1992; Xanthakis et al., 2014). Nevertheless, there is not enough information to analyse these experiments by a modelling approach. The thermophysical and dielectric properties of the food matrices (retina, pork, etc.) are unknown and the heat generated by the electromagnetic waves is not sufficiently controlled (multimode configuration). To overcome these problems and to carry out a deep analysis of these complex phenomena, we consider a configuration that can be well controlled, in terms of both process and product considerations.

To improve the control of the microwave distribution, a rectangular waveguide section (86 x $43 \mathrm{~mm}$ for the TE10 fundamental mode at $2450 \mathrm{MHz}$ ) is set up in a vertical position (Figure 1). Methylcellulose gel is chosen as a food analogue product because of its thermophysical and dielectric properties, which are close to those of meat products. The methylcellulose gel is $30 \mathrm{~mm}$ thick, $86 \mathrm{~mm}$ long and $43 \mathrm{~mm}$ wide. The sample fills the entire rectangular waveguide section. Microwaves are applied from the beginning of the simulation by periodic pulses at $2450 \mathrm{MHz}$ for $30 \mathrm{~s}$ periods and are generated from the top of the product; such a strategy follows the work of Anese et al. (2012) and Xanthakis et al. (2014) in which power was emitted by pulses with a specific period. In our system, the upper surface of the product is exposed to gaseous nitrogen with a convective heat transfer coefficient (HTC) considered to be homogeneous over the entire surface.

\subsection{Equations and boundary conditions}


There are several ways to model heat transfer in food-analogue materials (Pham, 2006). The present model solves the heat equation (1) by a partial differential equation based on enthalpy formulation (2) integrating the latent heat of water solidification.

$$
\begin{gathered}
\frac{\partial T}{\partial t} \frac{\partial h}{\partial T} \cdot \rho-\nabla \cdot k \nabla T=Q \\
h=\left[C p_{n f}-\left(C p_{n f}-C p_{f}\right) \frac{x_{i c e}}{x_{f w}}\right] T+\left[L \cdot x_{f w}-\left(C p_{n f}-C p_{f}\right) \cdot T_{i f}\right] \frac{x_{f w}-x_{i c e}}{x_{f w}} \\
Q=\frac{1}{2} \omega \varepsilon_{0} \varepsilon^{\prime \prime}|E|^{2}
\end{gathered}
$$

For the phase change, the enthalpy approach was chosen because convergence is easier compared to the apparent specific heat method (Pham, 2006).

The heat equation includes the source term $\mathrm{Q}$, which corresponds to the heat generated by microwaves. In this case, Lambert's law cannot be used because dielectric properties evolve locally during freezing and the product thickness is not large enough compared to the penetration depth in the product. The heat generation is calculated by using the local electric field induced by microwaves (3). The local electric field is obtained by solving Maxwell's equations numerically (Dibben, 2001).

Product freezing is modelled following the ice mass fraction variation $\mathrm{x}_{\mathrm{ice}}$, i.e. frozen free water, and $\mathrm{x}_{\mathrm{ice}}$ is defined as a function of ice crystal radius:

$$
\begin{gathered}
x_{\text {ice }}=\frac{m_{\text {ice }}}{m_{t}}=\frac{4 \cdot \pi}{3} \cdot r(T)^{3} \cdot N \cdot \frac{\rho_{\text {ice }}}{V_{t} \cdot \rho_{t}} \\
N=\frac{V_{\text {ice }}}{V_{c r}}=\frac{V_{t} \cdot \rho_{t}}{\rho_{\text {ice }}} \cdot x_{f w} \cdot \frac{3}{4 \cdot \pi \cdot r_{f i n}^{3}}
\end{gathered}
$$

Ice crystals are assumed to be spherical and to have the same radius. Their growth follows the temperature decrease as shown by equation (6).

$$
r(T)=\left(1+\frac{a}{T-T_{i f}-a}\right) \cdot r_{f i n}
$$

The final radius of ice crystals $r_{f i n}$ is set at $25 \mu \mathrm{m}$, the order of magnitude found in the literature (Anese et al., 2012; Xanthakis et al., 2014).

Thermophysical and dielectric properties, which evolve between fresh and frozen properties, are modelled according to the ice mass fraction variation $\mathrm{x}_{\text {ice }}$. This approach is similar to that based on the volume fraction (e.g. less than $2 \%$ variation for thermal conductivity). 


$$
\begin{gathered}
\varepsilon^{\prime}=\varepsilon_{n f}^{\prime} \cdot \frac{x_{l w}}{x_{f w}}+\varepsilon_{f}^{\prime} \cdot \frac{x_{i c e}}{x_{f w}} \\
\varepsilon^{\prime \prime}=\varepsilon_{n f}^{\prime \prime} \cdot \frac{x_{l w}}{x_{f w}}+\varepsilon_{f}^{\prime \prime} \cdot \frac{x_{i c e}}{x_{f w}} \\
k=k_{n f} \cdot \frac{x_{l w}}{x_{f w}}+k_{f} \cdot \frac{x_{i c e}}{x_{f w}} \\
\rho=\left(\frac{x_{l w}}{\rho_{n f} x_{f w}}+\frac{x_{i c e}}{\rho_{f} x_{f w}}\right)^{-1}
\end{gathered}
$$

The use of the ice fraction to fit the thermophysical and dielectric property variations is interesting because it only requires knowledge of their values in fresh and deep frozen states. The constant $a$ is the only parameter to fit the thermophysical and dielectric properties. The composition and thermophysical and dielectric properties of methylcellulose gel obtained from the literature are listed in Table 1. The dielectric properties and the mass ice fraction are represented in Figure 2.

It is assumed that the volume does not evolve with density variation by supposing a small pressure increase whose effect on transfer phenomena can be neglected. The walls of the waveguide are perfectly insulated and are considered to be perfectly conducting. The microwaves crossing the product without being dissipated are assumed to be absorbed by a water load located at the bottom end of the waveguide without any reflection (Akkari et al., 2005; Curet et al., 2014). Convection at the bottom surface of the sample is neglected because of thermal insulation by polystyrene.

These coupled equations are solved numerically with an unsteady state in $2 \mathrm{D}$ using the finite element simulation software COMSOL Multiphysics 5.2. The maximum resolution step time is $0.1 \mathrm{~s}$ with $1 \mathrm{~s}$ sampling to obtain sufficient accuracy due to the short duration of the microwave pulses. A small mesh sensitivity near the top surface temperature was observed. The quadrangle mesh size was therefore reduced by $50 \%$ until a relative RMSD lower than $5 \%$ was obtained.

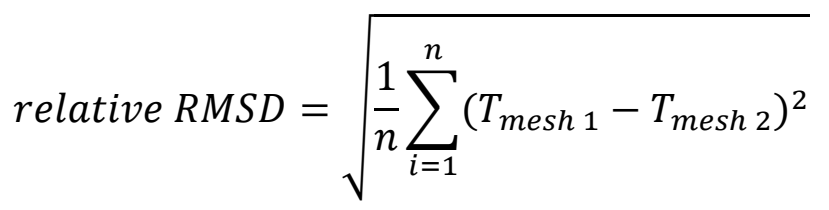

For the satisfactory mesh element size $(1.75 \mathrm{~mm})$, the computational time ranges between $30 \mathrm{~h}$ and $72 \mathrm{~h}$ depending on the configuration. Simulations are performed with 256 Go RAM and the processor Intel® Xeon ${ }^{\circledR}$ CPU E5-2680 v3 (12 cores, $\left.2.50 \mathrm{GHz}\right)$. 


\section{Results}

\subsection{Model validation against the literature data}

Two validation steps were carried out by comparison with data from previous works. The heat transfer model was validated against the results obtained from a 1D model based on the apparent heat capacity method, itself validated against experimental data (Rouaud and LeBail, 2015). This study was a cryogenic freezing with nitrogen gas $\left(-80^{\circ} \mathrm{C}\right)$ and a convective coefficient of $30 \mathrm{~W} \cdot \mathrm{m}^{-2} \cdot \mathrm{K}^{-1}$ for flat slab $2 \mathrm{~cm}$ thick of methylcellulose. The slab was sufficiently large to assume $1 \mathrm{D}$ transfer $(20 \mathrm{~cm} \mathrm{x} 10 \mathrm{~cm})$ and was further surrounded by polystyrene foam to ensure thermal insulation. Experiments were performed in a cryogenic chamber (CCF 40 - L'Air Liquide). Thermocouples, connected to a data logger, were inserted in the centre of slabs at 3 different depths to measure temperature versus time. It can be observed that the thermal kinetics at 3 locations coincided well between results obtained by Rouaud and Le-Bail (2015) and our modelErreur! Source du renvoi introuvable.. The small difference is due to the mass transfer, which is not taken into account in the current model. We can consider that our approach is validated, especially the determination of the ice fraction and its use to determine the thermophysical properties for $a=0.6$. Microwave modelling was validated against the available microwave tempering data of a product at an initial temperature of $-20^{\circ} \mathrm{C}$. These numerical data were obtained using the most reliable dielectric properties of methylcellulose in a frozen state provided by Curet (2008). In this work, optical fibres were inserted in a frozen bloc of methylcellulose $5 \mathrm{~cm}$ thick filling a waveguide in fundamental mode TE10 at $2450 \mathrm{MHz}(86$ x $43 \mathrm{~mm})$. Temperature was measured at different locations as a function of time to validate the model. It was then used to highlight temperature and electric variation within the entire product. Figure 4 shows the heterogeneous spatial distribution of temperature after $14 \mathrm{~s}$ of microwave tempering at 500 W. Our results are also in very good agreement in this second configuration. The determination of dielectric properties from the ice fraction appears to be relevant. As the model operates well for both cryogenic freezing and microwave heating, it can be used to study pulsed MAF.

\subsection{Microwave assisted freezing (MAF) process}

\subsubsection{Temperature evolution}

Microwaves reach the product on its top surface, which is also subjected to a nitrogen gas flow (Figure 1). We consider that the nitrogen gas is at $-80^{\circ} \mathrm{C}$ and the exchange with the 
surface is characterised by an HTC of $30 \mathrm{~W} \cdot \mathrm{m}^{-2} \cdot \mathrm{K}^{-1}$. The freezing front and the microwave propagations are thus both in the same direction. The initial product temperature is set at $5^{\circ} \mathrm{C}$. This process is simulated for several duty cycles: from $10 \%$ to $100 \%$ while keeping a mean power of $20 \mathrm{~W}$, which means $600 \mathrm{~J}$ per period (Figure 5).

Temperature is plotted for 3 points located on the central axis of the product at three depths $(0 \mathrm{~cm} ; 1.5 \mathrm{~cm} ; 3 \mathrm{~cm})$ for different pulse durations: $10 \%, 20 \%, 40 \%$ and $100 \%$ of the $30 \mathrm{~s}$ period (Figure 6). The shapes of the temperature curves are the same whatever the microwave pulse duration. They appear superimposed on Figure 6 because, at this scale, the resolution does not reveal the oscillations due to the microwave pulses.

This is a relevant result because the average power delivered to the product, and thus the amount of energy, is always the same (Figure 5). In order to observe differences between these curves, especially the temperature oscillations expected due to the microwave pulses, a zoom has to be made on a small part of the curve (Figure 7). The oscillations are quite small and the temperature difference $(\Delta \mathrm{T})$ with temperature curves for microwaves that have been generated continuously does not exceed $0.1^{\circ} \mathrm{C}$. It should be mentioned that these results can be connected to the experimental ones obtained by Xanthakis et al. (2014) who registered temperature oscillations due to microwave pulses. Nevertheless, their experimental conditions (multi-mode cavity) do not allow extensive comparisons.

With the model, it can be noted that $\Delta \mathrm{T}$ is larger for shorter pulse durations because the same amount of energy is transmitted in less time and induces a faster increase in temperature. While observing the temperature oscillations around the initial freezing temperature, a significant attenuation of the amplitude of $\Delta \mathrm{T}$ can be observed with the beginning of the phase change, at the freezing front, at $\mathrm{T}=\mathrm{T}_{\text {if }}$ (Figure 7). This shows the influence of the water phase change on the product dielectric properties, which govern the generated heat. The decrease in the dielectric loss factor explains the reduction in heat generated locally by microwaves.

\subsubsection{Hot spot displacement}

The interest of the modelling approach lies in the possibility of analysing the interaction between thermal and electromagnetic phenomena. For example, in Figure 8, which represents the electric field distribution after $1 \mathrm{~s}$ and $90 \mathrm{~min}$ of MAF, the evolution of both the location and amplitude of local electric field maxima can be observed. At the two MAF times, some electric field resonance occurs but, in the frozen state, fewer local maxima of higher value can be seen within the product. In this study, the product thickness is of the same order of magnitude as the penetration depth in a fresh sample: too short to obtain an exponential 
decrease, too large to obtain a resonating regime (see the electric field at $1 \mathrm{~s}$ in Figure 9). Microwaves are attenuated while showing resonances, which could be described as a kind of hybrid regime (Curet et al., 2009). It is possible to see nodes where the electric field is minimal and antinodes where it is maximal. These antinodes are also locations of hot spots, at which the heat generation is maximal (Figure 9).

To illustrate this, Figure 10 represents the generated heat distribution within the product for $1 \mathrm{~s}$ and $30 \mathrm{~min}$ of process, respectively; the displacement of hot spots can be observed. The advance of the freezing front, defined as the location where $\mathrm{T}=\mathrm{T}_{\mathrm{if}}$, induces a decrease in the dielectric properties in the upper part of the sample, which enables microwaves to be less and less attenuated. Thus, the hot spots move with the evolution of the freezing front location.

In a process without a phase change, the location of hot spots does not change drastically. In fact, in the temperature range studied, the dielectric properties are assumed to be constant in both the fresh and frozen state of the product. However, in MAF, the decrease in dielectric properties due to the phase change leads to a displacement of the location of local electric field maxima and hot spots (Figure 9). Figure 11 shows freezing front and hot spot locations as a function of time on the central axis of the product, where the electric field is larger due to the fundamental TE10 mode. At the beginning of the process, 4 hot spots are visible; hot spot \#1 located at the top surface follows the freezing front for almost $30 \mathrm{~min}$ (Figure 11). During this time and up to $0.015 \mathrm{~m}$ in depth (mid-thickness), the location of the freezing front is the same as this hot spot. A merging of hot spots \#1 and \#2 at $0.0143 \mathrm{~m}$ in depth after $26 \mathrm{~min}$ of treatment can also be observed in Figure 11. After $30 \mathrm{~min}$, the upper hot spot \#5 moves upward while hot spot \#1 that followed the freezing front starts to leave it and move upward like hot spot \#3 (Figure 11).

\subsubsection{Effect of the evolution of dielectric properties}

The displacement of these hot spots is due to an evolution of the electric field strength within the product. In fact, the advance of the freezing front results in a decrease in local dielectric properties. Thus, it induces 3 major effects: i) less microwave reflection at the top air/product interface because the gap in dielectric properties between the two media becomes smaller; ii) an increase in the wavelength in the product, resulting in a larger distance between 2 local electric field maxima; iii) an increase in the penetration depth because less power is dissipated in heat locally (Basak, 2006; Dibben, 2001).

An important phenomenon in understanding hot spot displacement is the reflection at the bottom surface, which acts like a partial shortcut. At the beginning, when plotting the local maxima of heat generated as a function of product depth, a constant location of hot spots can 
be observed as a function of time in the fresh part. Like for a shortcut, the distance between the bottom surface and these constant hot spot locations, so the location of electric field maxima, is equal to half of the wavelength in the fresh part more or less the minimum element size $(\lambda=15.7 \pm 1.75 \mathrm{~mm})($ Figure 11$)$.

The advancing freezing front disrupts the electric field distribution within the product by decreasing dielectric properties locally. Thus, the product can be considered as two parts separated by the freezing front: the upper part, partially frozen, where the dielectric properties are heterogeneous; the lower part, still fresh, where the dielectric properties are constant. The freezing front acts as a reflection interface with complex phenomena of reflection occurring at both the bottom surface and the freezing front. It induces the displacement of electric field maxima and hot spots.

\subsubsection{Generated heat}

The generated heat, which corresponds to the source term of the heat equation, is proportional to the relative dielectric loss factor and the square of the local electric field. In the fresh state, the dielectric constant and the dielectric loss factor are larger (Figure 12). A larger dielectric constant results in a low microwave penetration depth. So in the fresh state, the generated heat is mostly due to the large dielectric loss factor. In the frozen state, the dielectric properties are low, which results in a greater microwave penetration depth and also in larger electric field values. Figure 13 shows the repartition of electric field on the central axis of the product as a function of time. The freezing front also depicted marks a visible separation between the zone still fresh where the electric field is weaker, and the region that is freezing where it is stronger. In frozen state, a large generated heat value is mostly due to the large value of the electric field. Figure 14 represents the heat generation on the central axis as a function of time. It is a 3D representation of Figure 11. It shows that the generated heat is the largest in the frozen phase and at the phase change interface on the freezing front. The large values of generated heat in the frozen state are obviously due to the electric field because of the very low values of the dielectric loss factor in this state. This is not common in microwave treatment like in microwave thawing, for which some studies have reported that the dielectric loss factor has a larger influence on temperature distribution in the frozen state (Curet et al., 2014). However, the large values of generated heat at the phase change interface result from the combination of dielectric loss factor and electric field. Close to the freezing front $\left(\mathrm{T}<\mathrm{T}_{\mathrm{if}}\right)$, there are strong gradients in dielectric properties. Thus, the electric field is not as large as in the frozen phase but larger than in the fresh phase. Similarly, the dielectric loss factor at the interface is not as large as in the fresh phase but larger than in the frozen phase. 
Even if both the dielectric loss factor and the electric field have a medium value, their combination results in a large generated heat value along the freezing front.

\section{Conclusion}

An innovative pulsed microwave assisted freezing process was modelled taking into account the evolution of the thermophysical and dielectric properties during the freezing of a methylcellulose gel. The model was based on an original enthalpy formulation including the latent heat due to the ice crystal radius growth. It was successfully validated against the literature data. Numerical simulation demonstrated and quantified the temperature oscillations due to the microwave pulses. As observed in experiments from the literature, the freezing front was particularly affected by these oscillations. The model predicted a temperature amplitude close to $0.1^{\circ} \mathrm{C}$.

Hot spot displacements were observed and explained by studying the microwave reflection at interfaces and also by the modifications of dielectric properties induced by the phase change. Future works are planned to improve the model by taking into account supercooling and by adding a crystal growth model in order to induce a crystal size distribution in the product. It will then be used to study the influence of microwaves on frozen product quality and to provide further help in designing an industrial process.

\section{Acknowledgments}

This work received financial support from the French National Research Agency (ANR) under the FREEZEWAVE project (ERANET call "SUSFOOD”, grant number ANR-14SUSF-0001). The PhD of M. SADOT is co-funded by the FREEZEWAVE project and the Région Pays de la Loire.

\section{References}

Akkari, E., 2007. Modélisation et commande de la décongélation par micro-ondes. Thèse de I'Université de Nantes.

Akkari, E., Chevallier, S., Boillereaux, L., 2005. A 2D non-linear "grey-box" model dedicated to microwave thawing: Theoretical and experimental investigation. Comput. Chem. Eng. 30, 321328. doi:10.1016/j.compchemeng.2005.09.008

Anese, M., Manzocco, L., Panozzo, A., Beraldo, P., Foschia, M., Nicoli, M.C., 2012. Effect of radiofrequency assisted freezing on meat microstructure and quality. Food Res. Int. 46, 50-54.

Basak, T., 2006. Influence of various shapes of annular metallic support on microwave heating of 2D cylinders. Chem. Eng. Sci. 61, 2023-2034.

Basak, T., 2003. Analysis of resonances during microwave thawing of slabs. Int. J. Heat Mass Transf. 46, 4279-4301.

Basak, T., Ayappa, K.G., 1997. Analysis of microwave thawing of slabs with effective heat capacity 
method. AIChE J. 43, 1662-1674.

Bevilacqua, A., Zaritzky, N.E., Calvelo, A., 1979. Histological measurements of ice in frozen beef. J. Food Technol. 14, 237-251.

Bremer, P.J., Ridley, S.C., 2004. Safety of Frozen Foods, in: Hui, Y.H., Cornillon, P., Guerrero Legaretta, I., Lim, M.H., Murrell, K.D., Nip, W.-K. (Eds.), Handbook of Frozen Foods. New York, pp. 595618.

Chourot, J.M., Macchi, H., Fournaison, L., Guilpart, J., 2003. Technical and economical model for the freezing cost comparison of immersion, cryomechanical and air blast freezing processes. Energy Convers. Manag. 44, 559-571.

Curet, S., 2008. Traitements micro-ondes et transferts de chaleur en milieu multiphasique. Thèse de I'Université de Nantes.

Curet, S., Rouaud, O., Boillereaux, L., 2014. Estimation of Dielectric Properties of Food Materials During Microwave Tempering and Heating. Food Bioprocess Technol. 7, 371-384.

Curet, S., Rouaud, O., Boillereaux, L., 2009. Effect of Sample Size on Microwave Power Absorption Within Dielectric Materials: 2D Numerical Results vs. Closed-Form Expressions. AIChE J. 55, 1569-1583.

Dalvi-isfahan, M., Hamdami, N., Xanthakis, E., Le-bail, A., 2017. Review on the control of ice nucleation by ultrasound waves, electric and magnetic fi elds. J. Food Eng. 195, 222-234.

Delgado, A.E., Sun, D.-W., 2001. Heat and mass transfer models for predicting freezing processes - a review. J. Food Eng. 47, 157-174.

Dempsey, P., Bansal, P., 2012. The art of air blast freezing: Design and efficiency considerations. Appl. Therm. Eng. 41, 71-83.

Devine, C.E., Bell, R.G., Lovatt, S., Chrystall, B.B., 1996. Red Meat, in: Jeremiah, L.E. (Ed.), Freezing Effects on Food Quality. New York, pp. 51-83.

Dibben, D., 2001. Electromagnetics: Fundamental Aspects and Numerical Modeling, in: Datta, A.K., Anantheswaran, R.C. (Eds.), Handbook of Microwave Technology for Food Applications. New York, pp. 1-31.

Hanyu, Y., Ichikawa, M., Matsumoto, G., 1992. An Improved Cryofixation Method - Cryoquenching Of Small Tissue Blocks During Microwave Irradiation. J. Microsc. 165, 255-271.

International Institute of Refrigeration, 1986. Recommendations for the processing and handling of frozen foods, third. ed. Paris.

Jackson, T.H., Ungan, A., Critser, J.K., Gao, D., 1997. Novel microwave technology for cryopreservation of biomaterials by suppression of apparent ice formation. Cryobiology 34 , 363-72.

Kalichevsky, M.T., Knorr, D., Lillford, P.J., 1995. Potential food applications of high-pressure effects on ice-water transitions. Trends Food Sci. Technol. 6, 253-259.

Le Bail, A., Chevalier, D., Mussa, D.M., Ghoul, M., 2002. High pressure freezing and thawing of foods: a review. Int. J. Refrig. 25, 504-513.

Lim, M.H., McFetridge, J.E., Liesebach, J., 2004. Frozen Food Components and Chemical Reactions, in: Hui, Y.H., Cornillon, P., Guerrero Legaretta, I., Lim, M.H., Murrell, K.D., Nip, W.-K. (Eds.), Handbook of Frozen Foods. New York, pp. 67-81.

Liu, C.M., Wang, Q.Z., Sakai, N., 2005. Power and temperature distribution during microwave thawing, simulated by using Maxwell's equations and Lambert's law. Int. J. Food Sci. Technol. 40, 9-21.

Mallett, C., 1993. Frozen Food Technology, Springer. ed.

Nelson, S.O., Datta, A.K., 2001. Dielectric properties of food materials and electric field interactions, in: Datta, A.K., Anantheswaran, R.C. (Eds.), Handbook of Microwave Technology for Food Applications. New York, pp. 69-114.

Pham, Q.T., 2006. Modelling heat and mass transfer in frozen foods: a review. Int. J. Refrig. 29, 876888.

Rouaud, O., Le-Bail, A., 2015. Optimizing Combined Cryogenic and Conventional Freezing with Respect to Mass Loss and Energy Criteria, in: Internationnal Congress of Refrigeration. Yokohama, Japan.

Tang, J., 2005. Dielectric properties of foods, in: Schubert, H., Regier, M. (Eds.), The Microwave Processing of Foods. Cambridge, pp. 22-40. 
Wang, L., Weller, C.L., 2012. Thermophysical Properties of Frozen Foods, in: Sun, D.-W. (Ed.), Handbook of Frozen Food Processing and Packaging. Boca Raton, pp. 101-127.

Woo, M., Mujumdar, A., 2010. Effects of Electric and Magnetic Field on Freezing and Possible Relevance in Freeze Drying. Dry. Technol. 28, 433-443.

Xanthakis, E., Le-bail, A., Havet, M., 2014. Freezing Combined with Electrical and Magnetic Disturbances, Second Edi. ed, Emerging Technologies for Food Processing. Elsevier Ltd.

Xanthakis, E., Le-Bail, A., Ramaswamy, H., 2014. Development of an innovative microwave assisted food freezing process. Innov. Food Sci. Emerg. Technol. 26, 176-181.

\section{Nomenclature}

a constant $K$

Cp specific heat capacity $J \cdot \mathrm{kg}^{-1} \cdot \mathrm{K}^{-1}$

E local electric field $V . m^{-1}$

$h \quad$ specific enthalpy $J . \mathrm{kg}^{-1}$

$k \quad$ thermal conductivity $W \cdot m^{-1} \cdot K^{-1}$

$L \quad$ solidification latent heat $J \cdot \mathrm{kg}^{-1}$

$N \quad$ number of crystals

$Q \quad$ heat source term W. $m^{-3}$

$r \quad$ crystal radius $m$

$T$ temperature $K$

$t \quad$ time $s$

$V \quad$ volume $m^{3}$

$x \quad$ mass fraction

\section{Greek symbols}

$\varepsilon_{0} \quad$ vacuum permittivity F.m ${ }^{-1}$

$\varepsilon$ "' relative dielectric loss factor

$\lambda \quad$ wavelength $m$

$\rho \quad$ density $k g . \mathrm{m}^{-3}$

$\omega \quad$ pulsation rad.s s $^{-1}$

$\varepsilon^{\prime} \quad$ relative dielectric constant

\begin{tabular}{ll}
\multicolumn{2}{l}{ Subscripts } \\
cr & crystal \\
$f$ & frozen \\
fin & final \\
$f w$ & freezable water \\
ice & ice \\
if & initial freezing \\
$l w$ & liquid freezable water \\
$n f$ & non-frozen \\
$t$ & total \\
$w$ & water
\end{tabular}




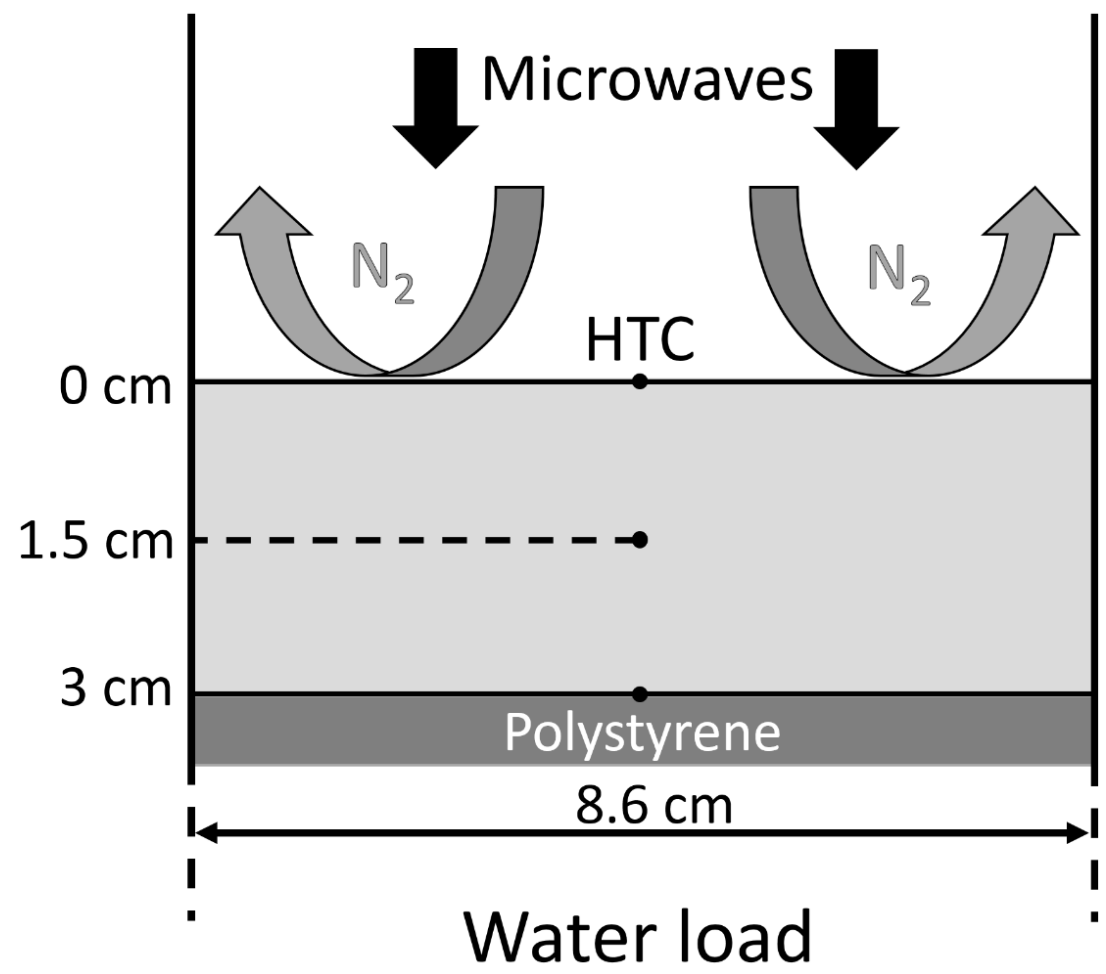

Figure 1. Schematic cross-section of the methylcellulose gel in the waveguide section 


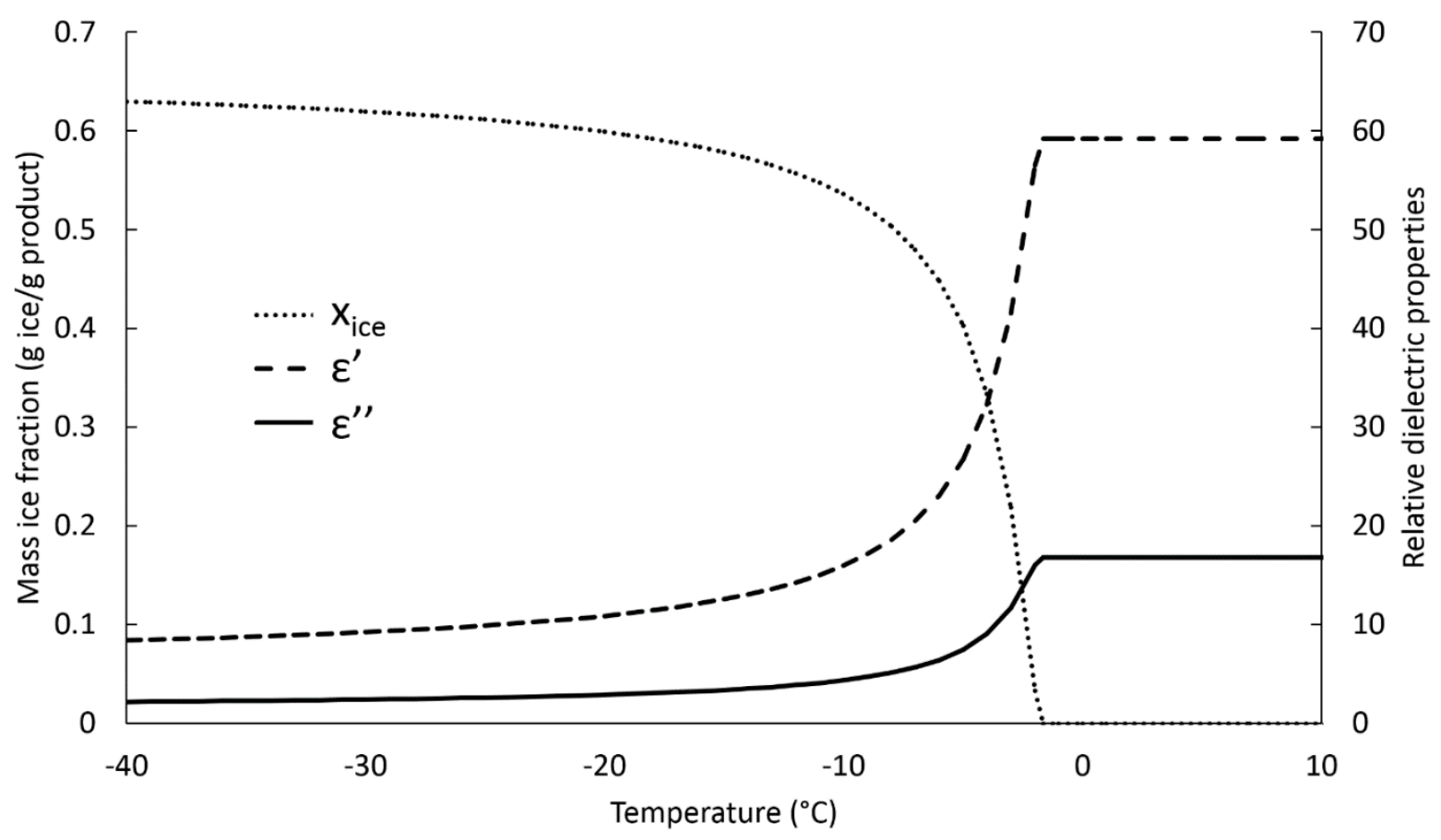

Figure 2. Evolution of the mass ice fraction and dielectric properties as a function of temperature. 


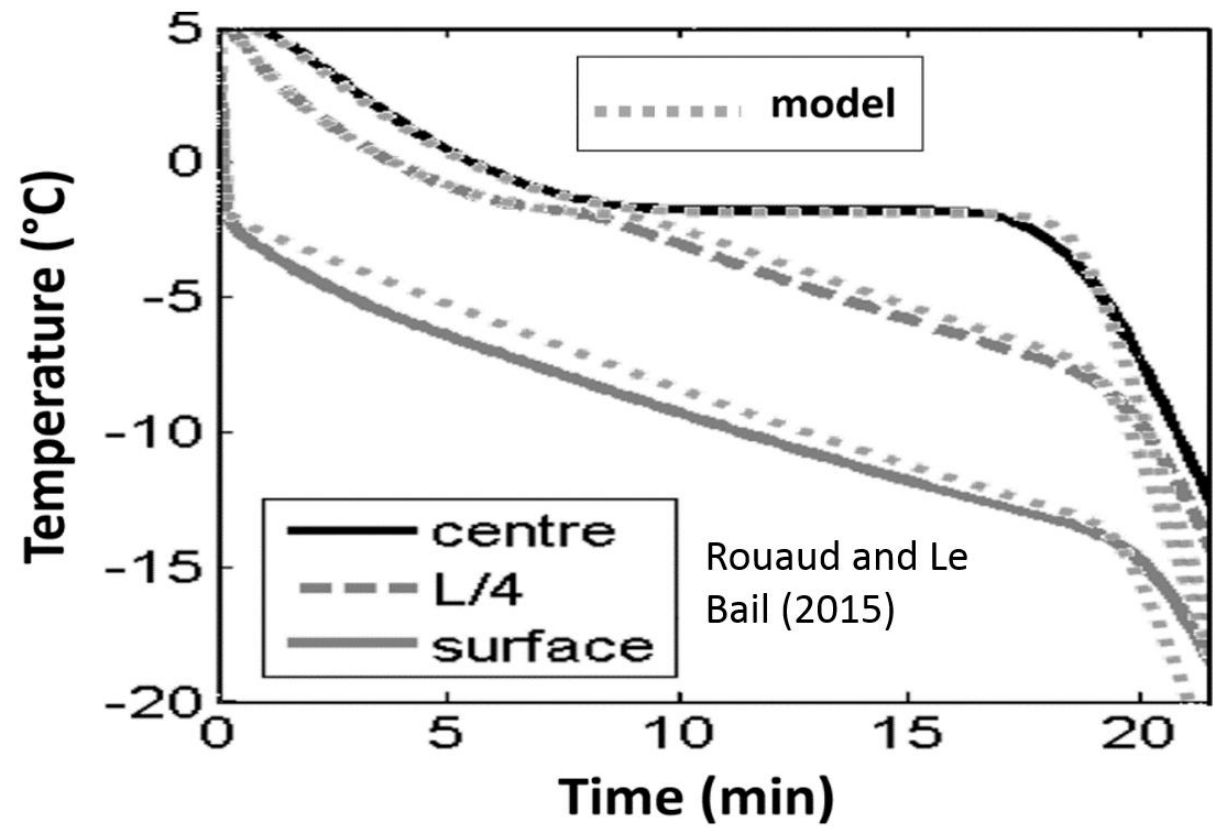

Figure 3. Temperature evolution in methylcellulose gel as a function of time during cryogenic freezing (Rouaud and Le-Bail, 2015) 


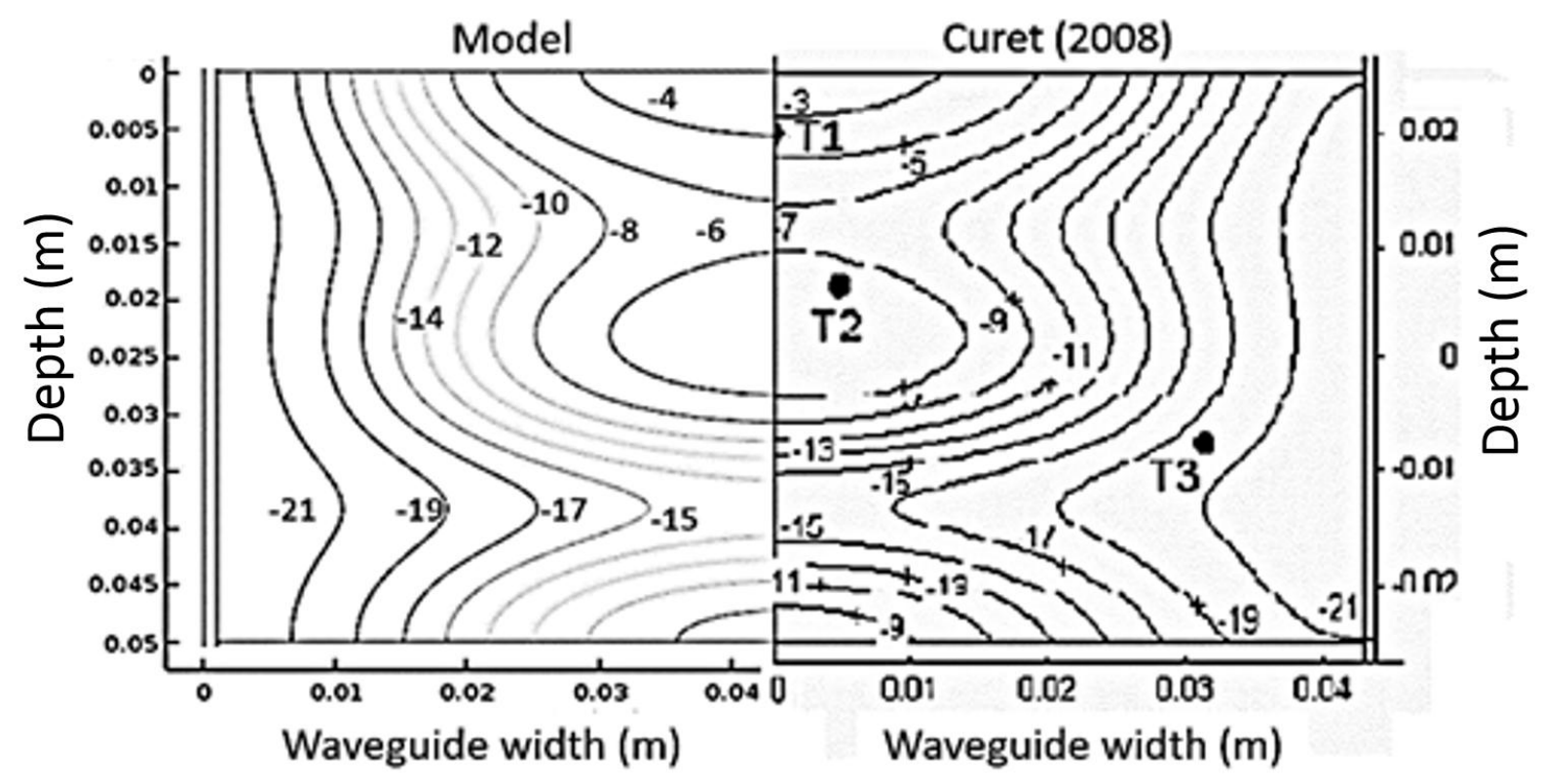

Figure 4. Temperature distribution in methylcellulose gel as a function of waveguide width and depth after 14 s of microwave tempering (current model and Curet (2008)) 


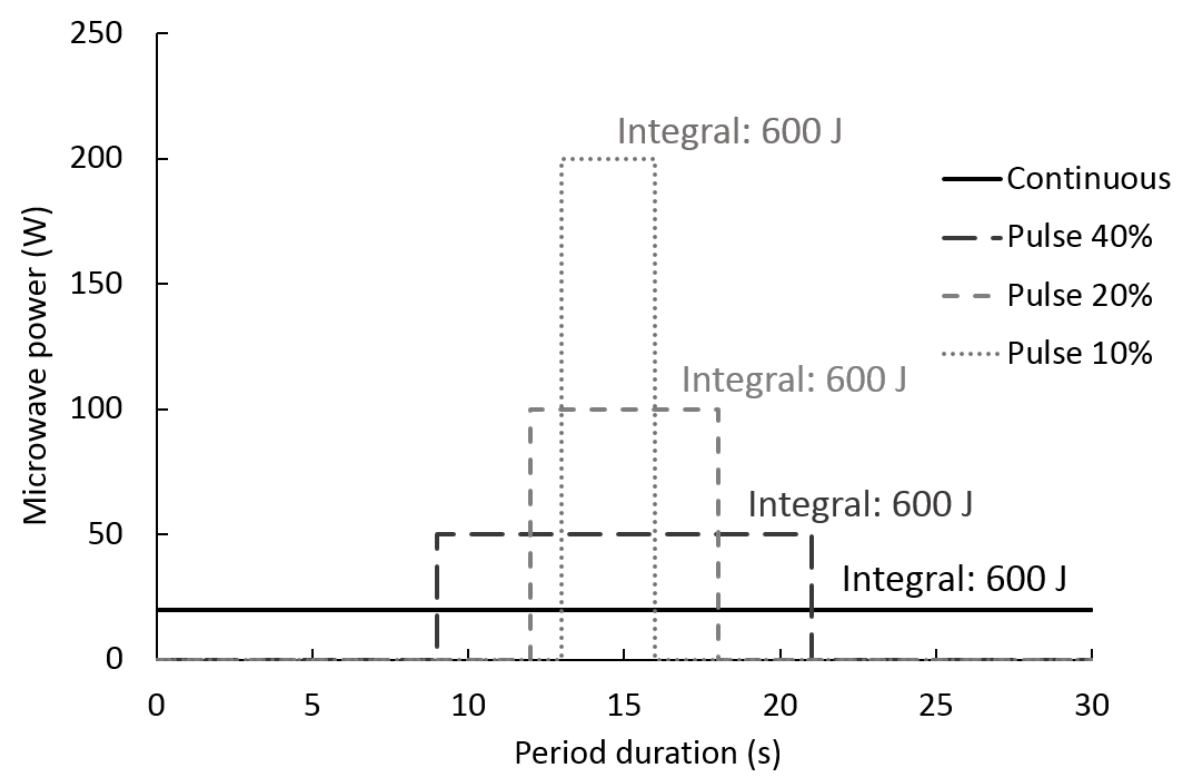

Figure 5. Power and duration of pulses for one period (30 s) 


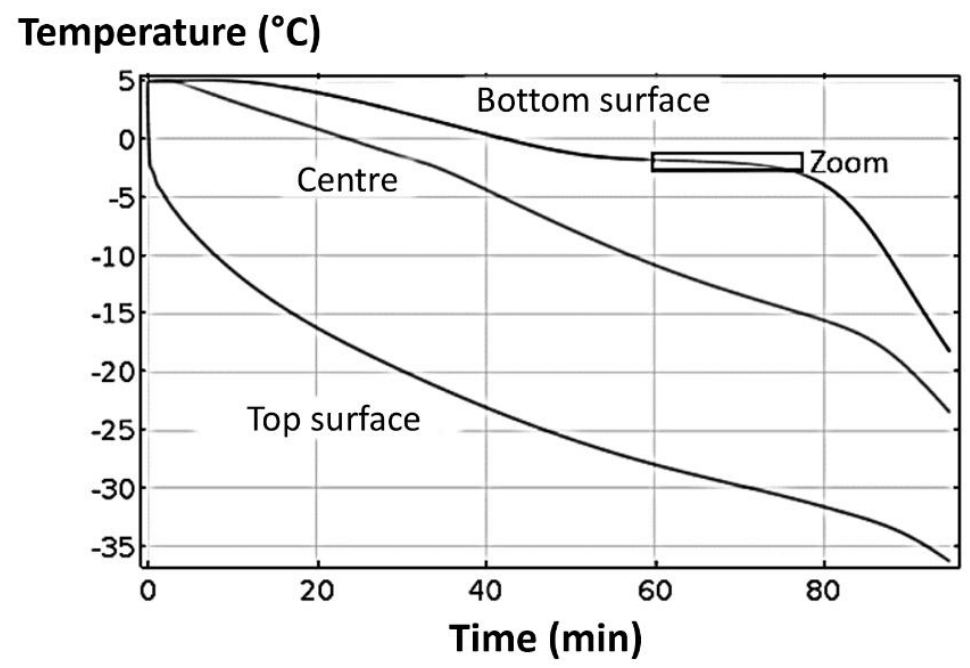

Figure 6. Temperature evolution in methylcellulose gel on the product central axis for continuously applied microwaves, pulsed at 10\%, 20\% and 40\% of the period duration (30 s). 

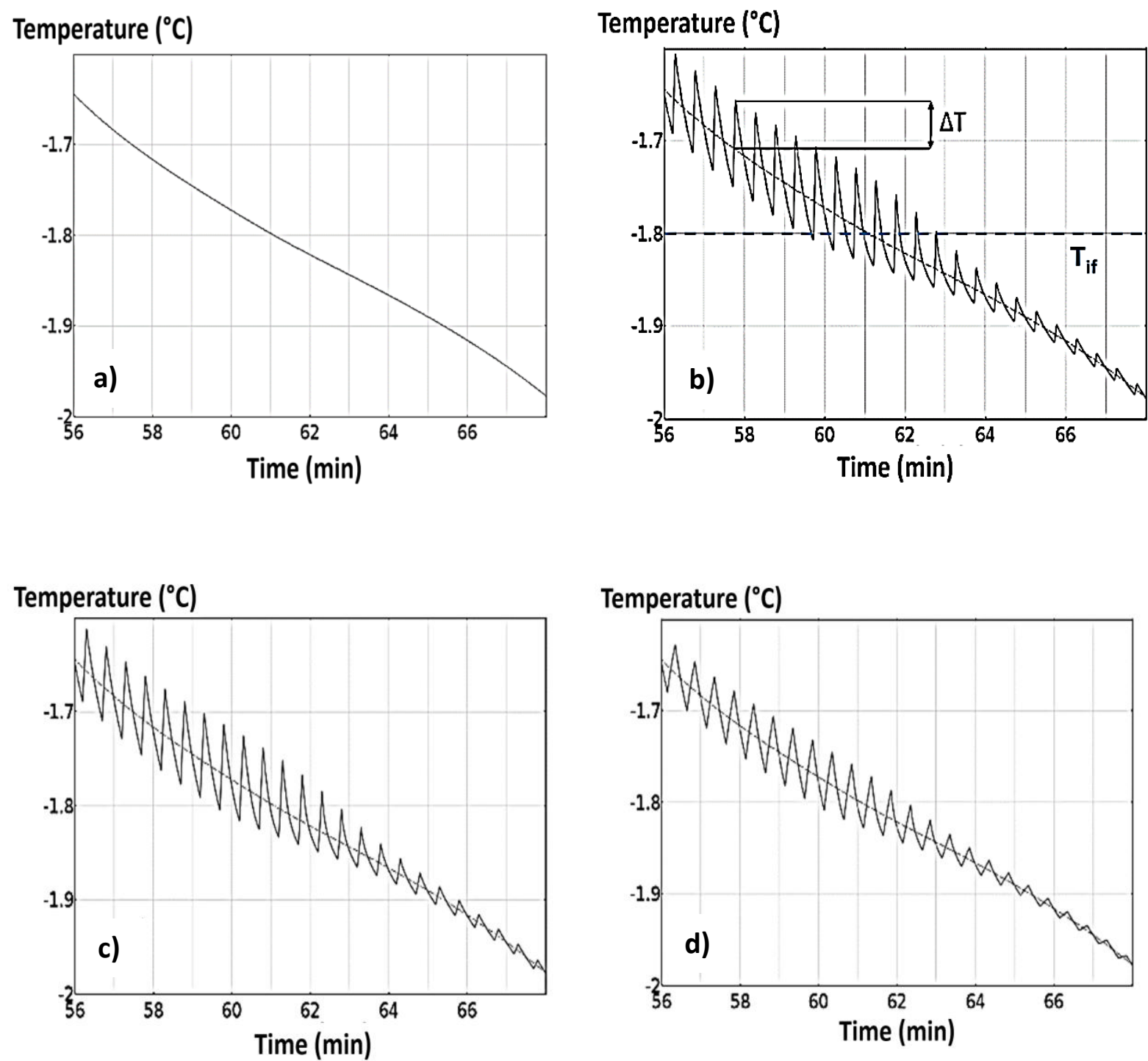

Figure 7. Zoom on the bottom surface temperature evolution for a) continuously applied microwaves; and pulsed microwaves at b) 10\%; c) 20\%; d) $40 \%$ of the period duration (30 s). 

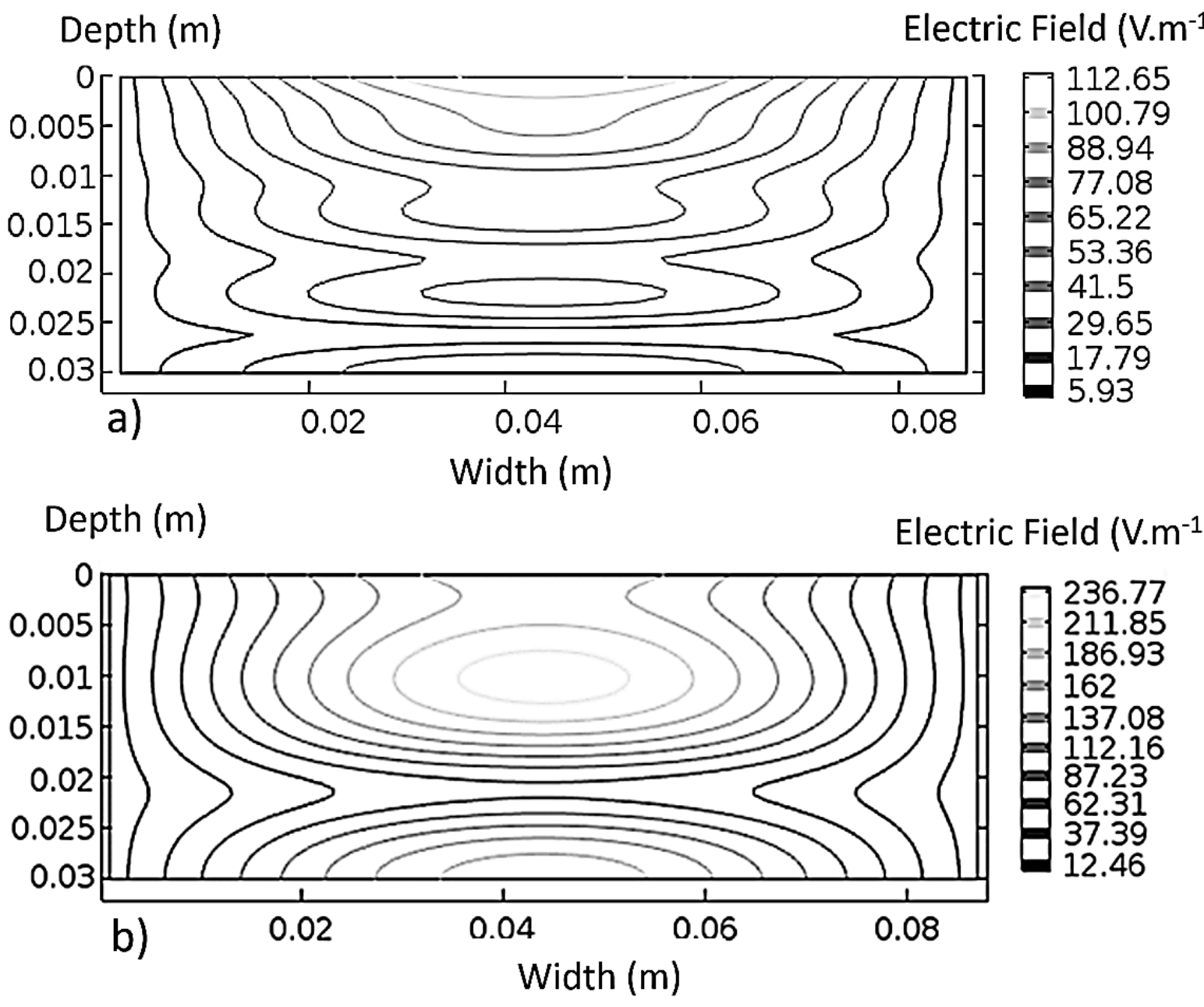

Figure 8. Electric field distribution after a) $1 \mathrm{~s}$ b) 1 h $30 \mathrm{~min}$ 
a)
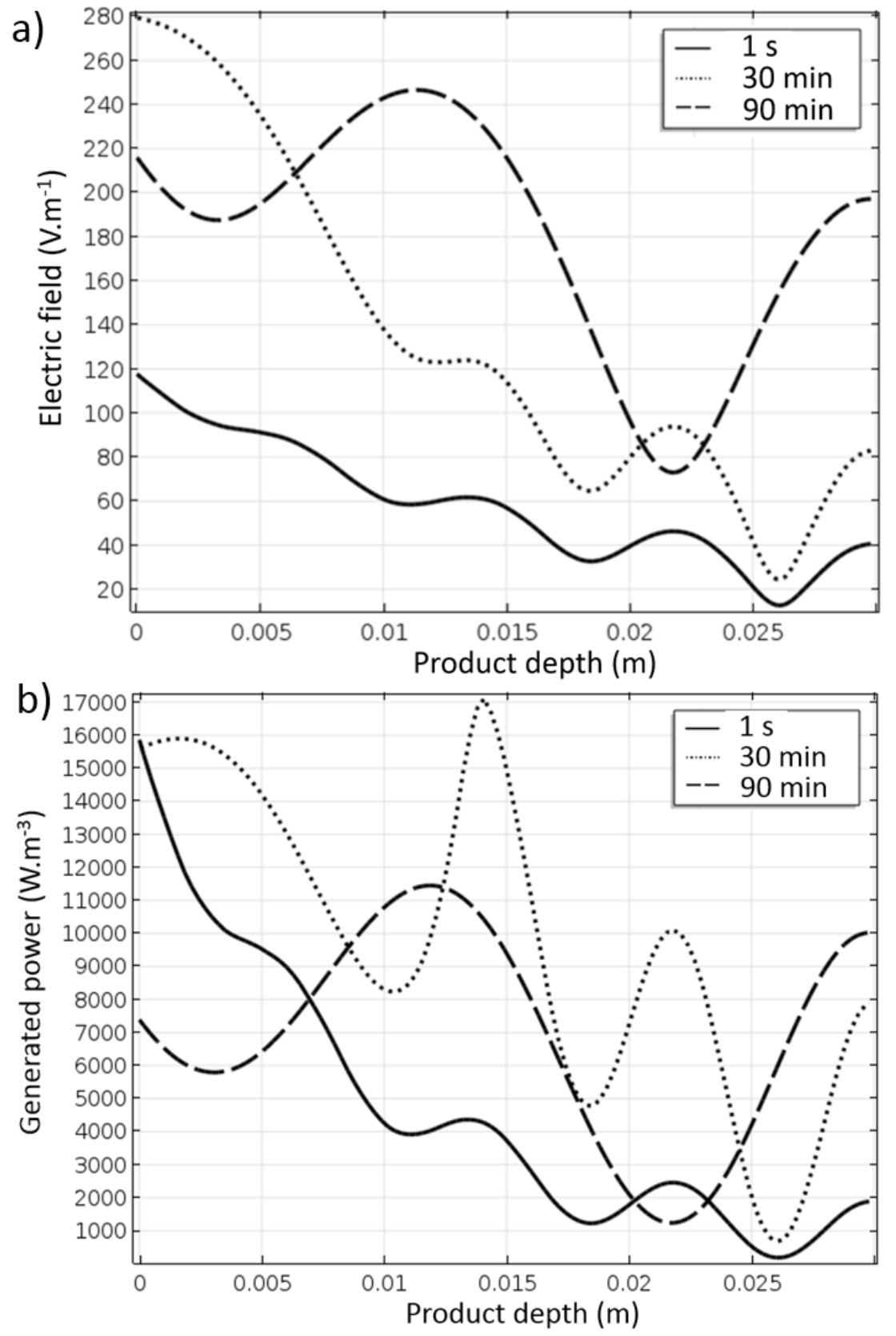

Figure 9. Distribution on the central axis of a) electric field b) generated heat as a function of product depth for $1 \mathrm{~s}, 30 \mathrm{~min}$ and $90 \mathrm{~min}$. 


\section{Depth (m)}

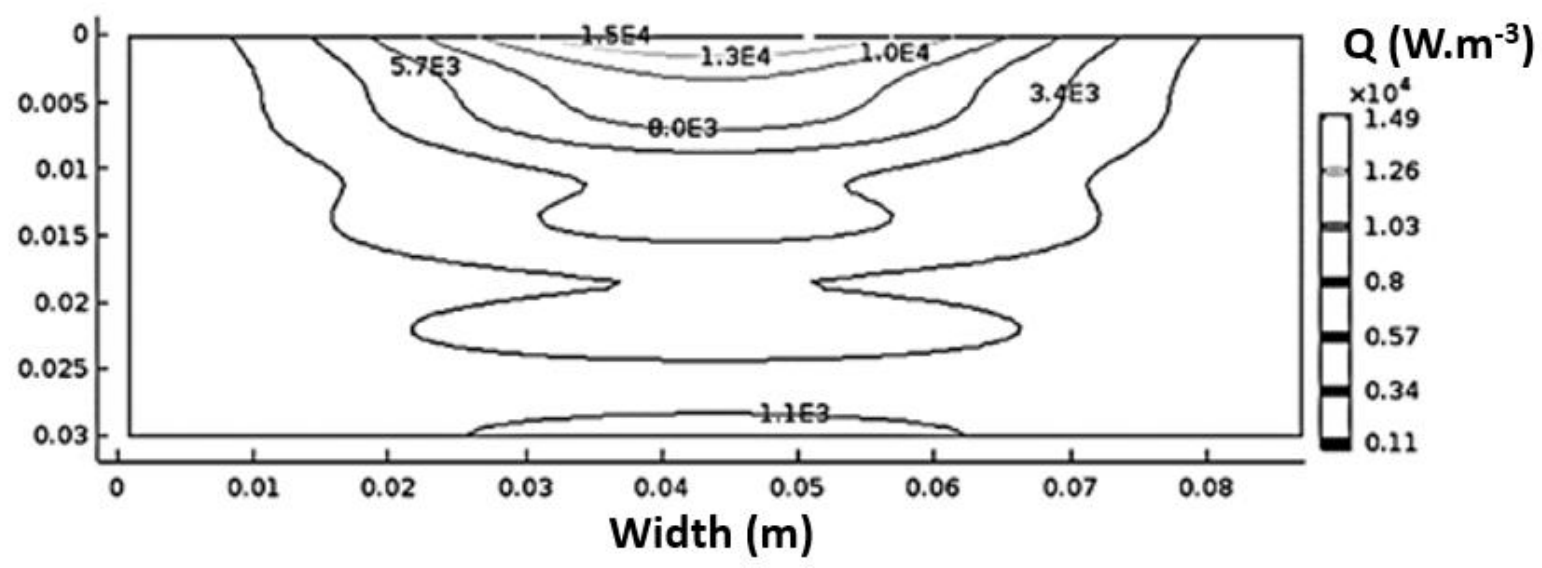

\section{Depth (m)}

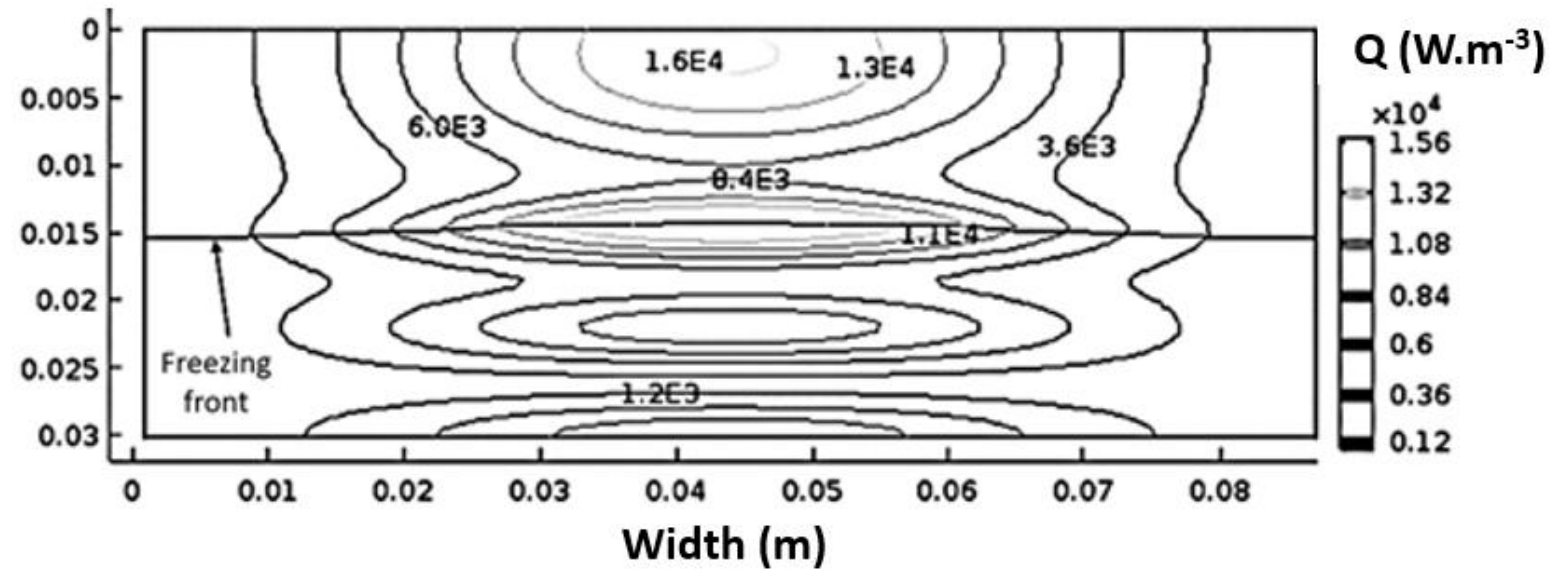

Figure 10. Heat source term distribution as a function of waveguide width and depth for a) a totally fresh product $(t=1 \mathrm{~s})$; b) after 30 min of MAF. 


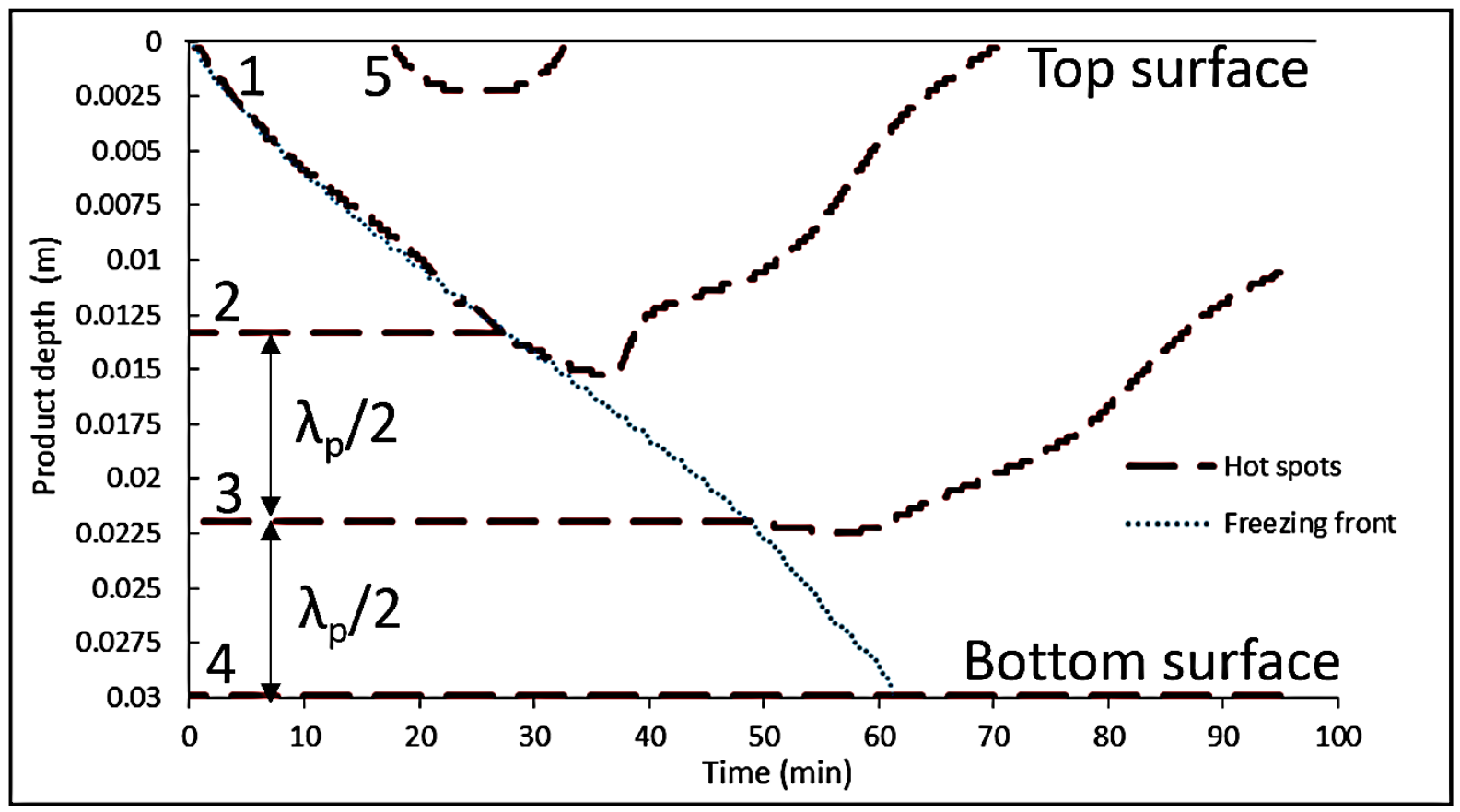

Figure 11. Location of hot spots and freezing front at the product central axis as a function of time. 


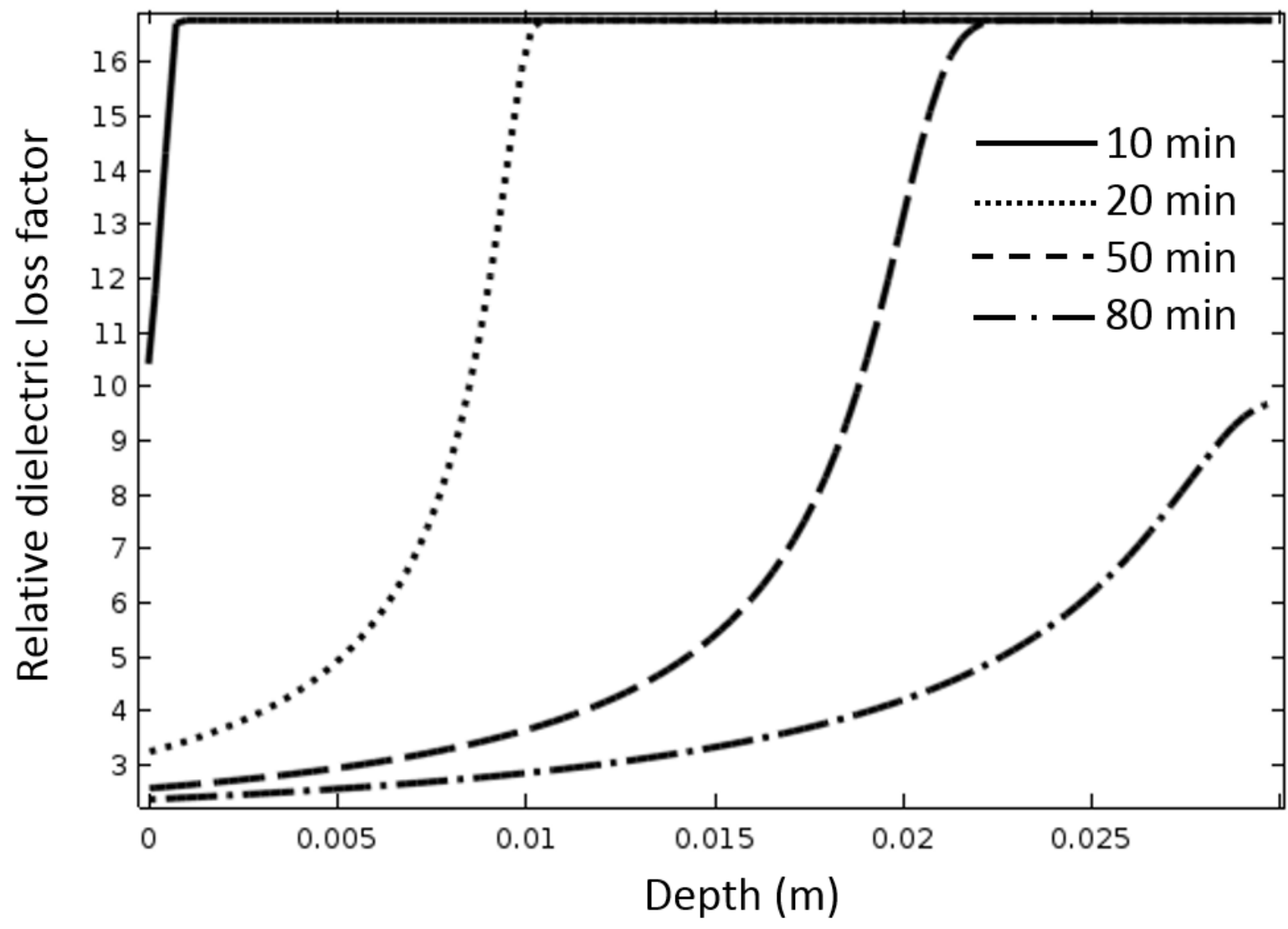

Figure 12. Relative dielectric loss factor as a function of product depth for 10, 20, 50 and $80 \mathrm{~min}$ of treatment. 


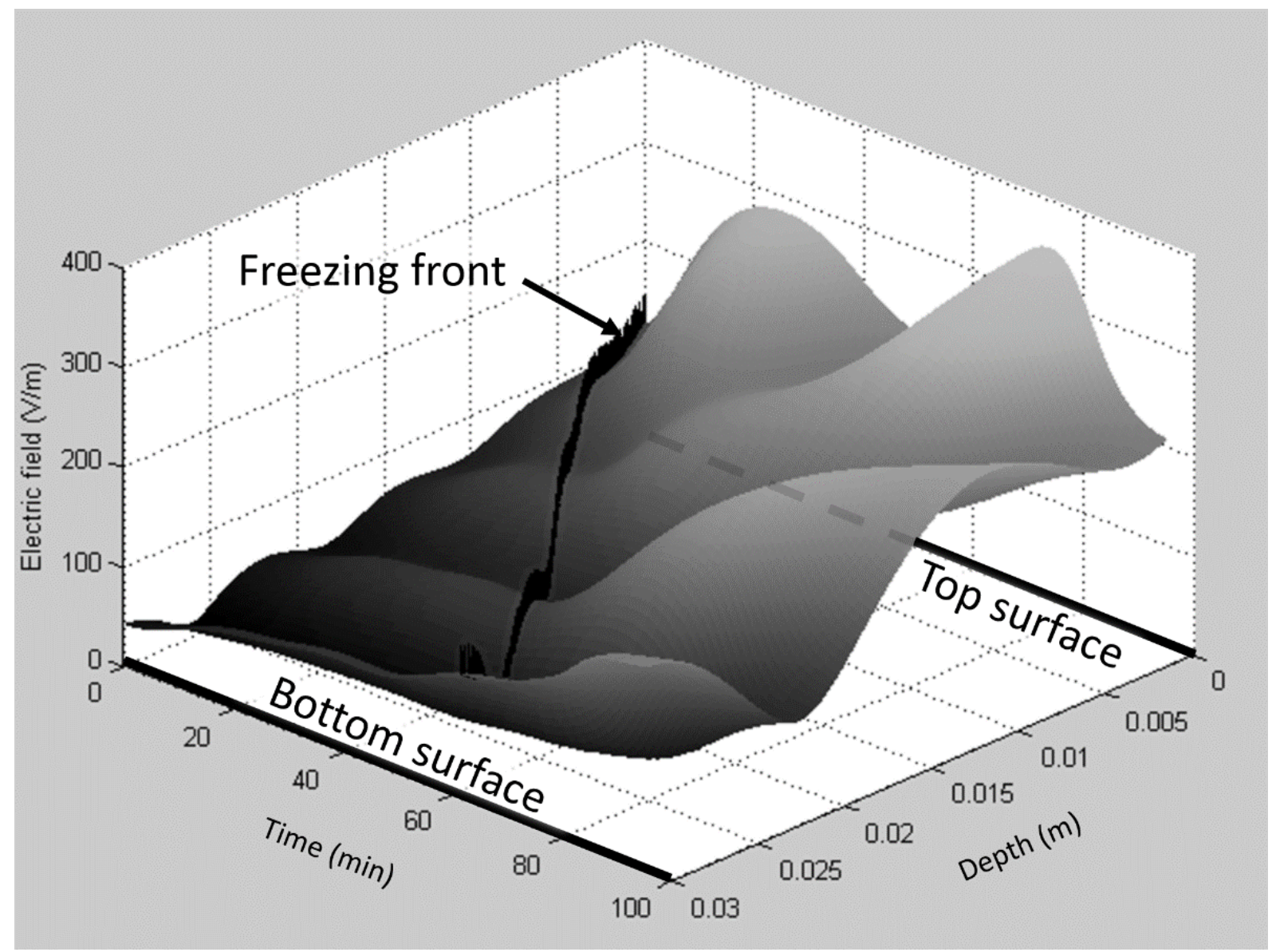

Figure 13. Electric field on the central axis of the product as a function of depth and time. 


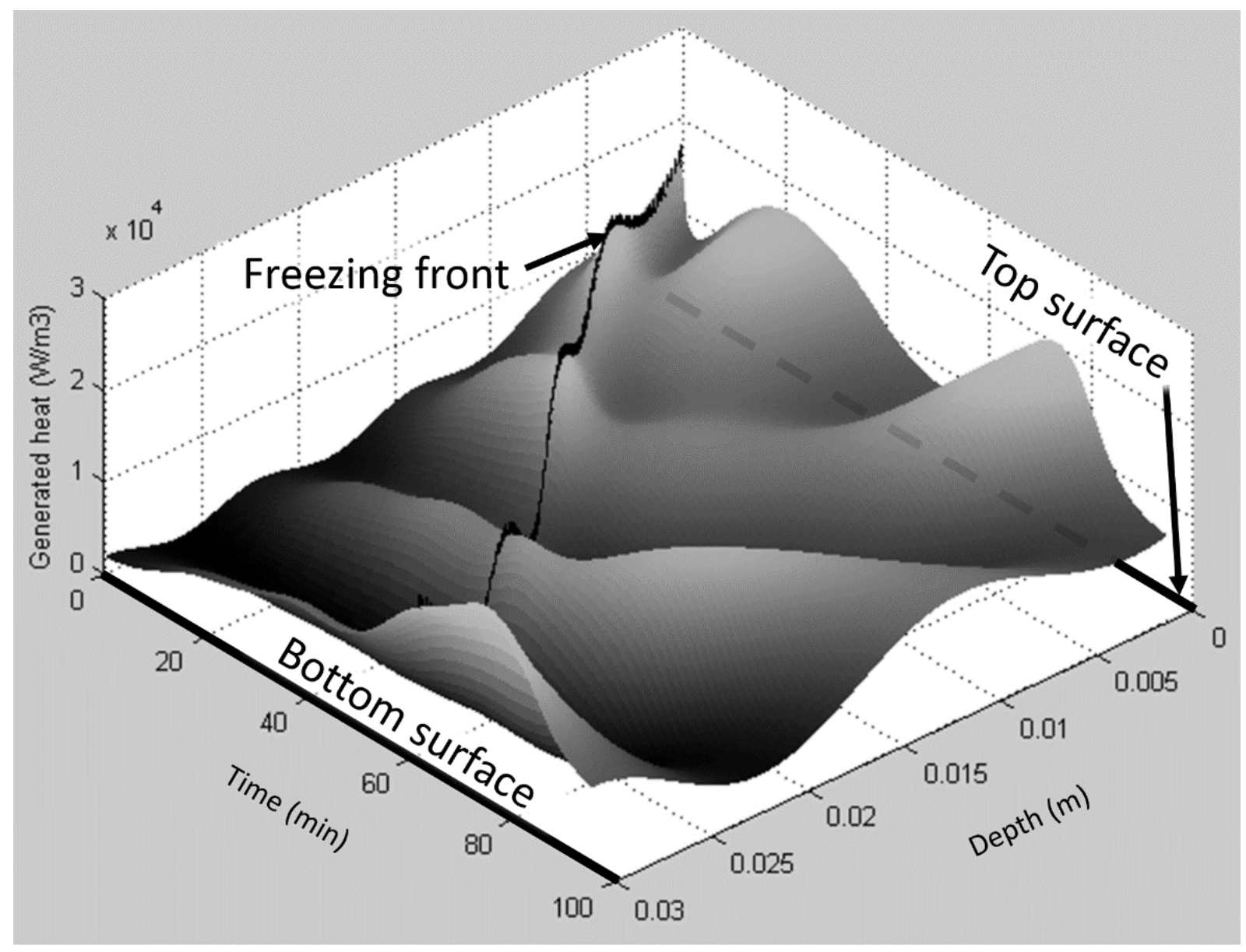

Figure 14. Generated heat on the central axis of the product as a function of depth and time. 
Table 1. Composition, thermophysical and dielectric properties of methylcellulose gel (Basak and Ayappa, 1997; Curet, 2008).

\begin{tabular}{cccccc}
\hline & $\varepsilon^{\prime}$ & $\varepsilon^{\prime \prime}$ & $\mathrm{Cp}$ & $\mathrm{k}$ \\
\hline \multirow{2}{*}{ Product } & & & $\mathrm{J}^{-\mathrm{kg}^{-1} \cdot \mathrm{K}^{-1}}$ & $\mathrm{~W} \cdot \mathrm{m}^{-1} \cdot \mathrm{K}^{-1}$ \\
\hline & Frozen & 6 & 1.5 & 2444.6 & 1.3 \\
\cline { 2 - 6 } & Fresh & 59.2 & 16.8 & 3824 & 0.5 \\
\hline$\rho$ & & $\begin{array}{c}\text { Bound water }+ \\
\text { (Free water) }\end{array}$ & $\begin{array}{c}\text { (Frozen free } \\
\text { water) }\end{array}$ & Dry matter \\
\hline $\mathrm{x}$ & $\mathrm{kg} \cdot \mathrm{m}^{-3}$ & 1000 & 917 & 1315 \\
\hline & & wet basis & $0.14+(0.66)$ & $(0,66)$ & 0.2 \\
\hline
\end{tabular}

